\title{
Features of choosing coping strategies by teenagers in the context of the risks of modern education
}

\author{
Zhanna Kara and Liudmila Kruteleva* \\ Southern Federal University, 344065, Rostov-on-Don, Russia
}

\begin{abstract}
The school environment is a complex microcosm where the younger generation learns to adapt to live in society. The problem of school bullying is in the highlight. The purpose of the research is to study the correlations between "bullying structures" of the teenagers, living in their own families and in social rehabilitation centers for minors, and their choice of coping strategies. The hypothesis of the research assumes that teenagers will prefer different coping strategies depending on their place in the bullying structure and the place of living. The sample consisted of 62 teenagers aged 12-13 years old. On the grounds of the theoretical research, we distinguished psychological and social prerequisites of the phenomenon of school bullying. We and state that aggression and anxiety displaying by teenagers in a group cooperation are predictors of a bullying situation. The psychological testing allowed us to reveal bullying structures, components of aggressive behavior and school anxiety, and preferable coping strategies of adolescents. Using the Spearman's rank correlation analysis enabled us to prove the hypothesis and to describe the preferable coping strategies of such bulling structures as "Bully", "Bully's assistant", "Defender", "Victim" and "Bystander" depending on the place of living of teenagers. The research has got a novelty and practical importance and the results are useful for work with teenagers in comprehensive schools and in social rehabilitation centers for minors.
\end{abstract}

\section{Introduction}

The modern world is changing rapidly. There has never been such a high speed in the transformation of society in the history of mankind. And information technologies take on an ever-increasing role in the process. This characteristic of life certainly affects a person. The increased information load is reflected on the psychological state of a person, the ability to cope with anxiety, the choice of a line of behavior for the possibility of a safe existence. The tension from the rapid changes and the external influence on adolescents leads to risks in the educational sphere associated with an informational behavior. The informational behavior itself has several meanings: acquiring new knowledge, implementing new teaching methods, meeting informational needs, etc. [1, 2]. In the context of the study, we consider an information behavior as a human behavior, which includes a set of actions based on the

\footnotetext{
* Corresponding author: zykara@sfedu.ru
} 
available and received information. The received information is transformed by a person judging from one's own individual characteristics and finds continuation in behavior. Attention to research in the field of strategies of human behavior remains in a great demand since the behavior determines the further direction of human development. The problem of this research is to study the peculiarities of choosing coping strategies by adolescents participating in bullying in the context of the risks of modern education.

The analysis of studies of strategies of human behavior indicates a constant interest in this topic, starting with R. Lazarus, S. Folkman, etc. [3]. In the modern world the study of coping strategies of a person is relevant for different ages, professional orientation, different places of residence, etc. K.S. Shalaginova et al, A.A. Rean, A.A. Stavtsev, K.D. Khlomov et al, and other psychologists characterize coping as a purposeful, constructive and conscious way of human response $[4,5,6]$.

The interrelations of behavior strategies with psychological and social phenomena have already been studied. There has been described that such personality characteristics as age, social role, religion, the level of anxiety, locus of control, self-esteem, self-acceptance, selfefficacy, belonging to a certain group, individual values, etc. act as predictors of certain coping strategies $[4,5,6]$. Behavior strategies help a person to be integrated into the system of the place of residence. Changes in the information space of society cause the changing behavior of adolescents both positively and negatively. But in is necessary to note the lack of research on choosing coping strategies by adolescents in the context of the risks of modern education to which we refer to bullying.

The self-affirmation of adolescents in the team, the search for one's own place in the school environment are the usual practice in an educational institution, and the choice of coping strategy plays an important role in this case. And one of the main problems in adolescence is a manifestation of a cruel treatment in relation to all participants of the educational institution, especially to their peers directly, which is called bullying.

The early publications on the topic of bullying include articles on school bullying by K. Dukes (1905) and subsequent systematic research concerning the problem of bullying by D. Olweus, C.R. Cook et al and others [7, 8].

The experience in various directions has been accumulated in recent years research.

H. Gaffney et al (2021) have examined "the relationship between the presence of specific components and the effectiveness in reducing bullying perpetration $(\mathrm{n}=82)$ and victimization $(\mathrm{n}=86)$ )" of adolescents [9].

They have revealed the school-bullying victimization outcomes depend on informal peer involvement and information for parents. And using meta-regression analyses they have proved that there is "no significant relationship between effectiveness and the number of intervention components included in a program" [9].

C. Viejo et al (2020) showed that the rates of involvement in bullying of adolescents living in Valencia reached $46.2 \%$, and the psychological dating aggression was rated at $31.4 \%$. They found out that the aggression manifested in bullying acted as a predictive variable for future displays of psychological aggression during situations unrelated to bullying. The authors underline the significance of experience gained in Primary School for the further both aggression and victimization of adolescents [10].

N. Sianko et al (2019) surveyed adolescents living in rural areas for four years and studied the influences of gender and ethnicity on their behavior. They have revealed that "perpetration increase steadily for males and females", while victimization depends on age, gender, and ethnicity [11].

E.A. Casey et al (2018) studied helping and bystander behavior among adolescents in the context of bullying. They found out that adolescents were more inclined to support victims of aggression than to interrupt perpetrators. The scientists highlight the importance of 
"providing coaching to respond to peer aggression in specific ways that maximize their own and others' safety and well-being" [12].

E. Khatcherian and N. Zdanowicz (2018) studied the identity of adolescents subjected to cyberbullying. The scientists have revealed that such adolescents are actively looking for friends for compensation of a true communication. These teenagers have problems in building and maintaining communication both among peers and among adults (parents, teachers), which affects the development of their identity [13].

C. Salmivalli (2010) focused on adolescent bullying as "a group process" and studied the motives of the participants and adaptation of victims in different contexts [14].

In Russia, bullying is investigated by I.A. Baeva, Yu.V. Obukhova, V.O. Guryeva, Yu.A. Rokitskaya, and others [2, 15, 16].

The definition of "bullying" given by D. Olweus [7] describes it as a systematic, purposed, aggressive behavior without designating characteristics of a subject and an object. D. Lane, E. Miller, and then K.S. Shalaginova and others define bullying as a conscious, psychological, physical, cruel and long-term process of the attitude of one student (or a group) to another (or others) [4]. K.D. Khlomov, D.G. Davydov, A.A. Bochaver defines "bullying" as an aggressive behavior in group of people got together involuntarily. The inevitability of being in such a group create conditions which can cause a negative tension [6].

Nowadays there is a distinction, and bullying is connected to a face-to-face, direct impact on a person, while cyberbullying is described as victimization mainly through social networks.

In our research we consider bullying as a cruel attitude of one person to another regardless of the type of aggressive behavior, who are forced to be in one group. The consequences of bullying usually have a negative influence of a person's life: depression, substance use, sexual promiscuity, suicidal tendency, etc. [6]. The specifics of bullying are reflected in its structure, which includes the victim, the bully (the initiator of the bullying), the bully's assistants (participants in the bullying who support the bully), the bystanders (Khlomov et al, Obukhova, Guryeva and others) $[6,15]$. Bullying researchers pay attention to the meaning and the impact on a person of any role and note that roles can be changed depending on the situation. Based on this, in our study the participants in bullying are adolescents as possible participants during the academic year.

As a result of the analysis of studies on the problems of school violence, we generalized the prerequisites of the phenomenon of school bullying. These prerequisites of a psychological and social nature include: 1) individual personality traits; 2) general characteristics of the family, relationships within the family, including communication styles; 3) social and psychological state and position of families (aggressors, victims); 4) the influence of the teacher's behavior; 5) the influence of the media broadcasting scenes of violence, and the absence of value of the human life; 6) the external environment (dangersafety); 7) management style at the state level (imperative) $[14,15,16]$.

On the grounds of theoretical analysis, we revealed the absence of studies aimed at investigating coping strategies of adolescents, participating in bullying, living in their own families and in social rehabilitation centers for minors, and studying in comprehensive schools.

According to above mentioned we consider that such psychological characteristics of teenagers as aggression and anxiety displaying in a group are a certain guideline for early detection of a bullying situation. Thus, the purpose of our research is investigating both the "bullying structures" of adolescents, living in their own families and in social rehabilitation centers for minors, and studying in comprehensive schools, and the peculiarities of their choice of coping strategies. 


\section{Methods}

\subsection{Participants}

The object of the study was 62 adolescents aged 12-13 years old who live in the Rostov region. The gender characteristic of the sample did not investigate. All of them were divided into 2 groups.

Group 1 includes adolescents living in their own families and studying in comprehensive schools.

Group 2 includes adolescents temporarily living in social rehabilitation centers for minors and studying in comprehensive schools. The adolescents temporarily live in social rehabilitation centers due to falling into a difficult life situation. The criteria for a difficult life situation are the following: a difficult financial situation of a family, a deviant family, nominally advantaged and disadvantaged ones. During the procedure of deprivation of parental rights, the social guardianship service sends a teenager for a temporary stay to a social rehabilitation center for minors. These adolescents need for a social assistance.

The representativeness of the sample is determined by a sufficient sample size.

\subsection{Research methods and techniques}

In our research we used such methods as theoretical analysis of scientific literature, testing, and statistical data processing.

In the empirical part of the research, we used the following diagnostic techniques: "The technique for identifying «bullying structure»" (E.G. Norkina), "Buss-Perry Aggression Questionnaire" (adapted by S.N. Enikolopov, N.P. Tsibulsky), "The school anxiety test" (by Phillips), "Strategic Approach to Coping Scale, SACS" (by S.E. Hobfoll adapted by N.E. Vodopyanova, E.S. Starchenkova).

The primary data processing was carried out by means of descriptive statistics, finding the average values from raw scores. We applied Spearman's rank correlation analysis to reveal the correlations between studied phenomena. The Statistica 13.3 software was used to process the obtained primary data.

\section{$3 \quad$ Results}

\subsection{The results of psychological diagnostics}

On the first stage of the empirical research, we carried out the psychological diagnostics of the teenagers.

By means of "The technique for identifying «bullying structure»" (E.G. Norkina) we determined the "bullying structures" inherent in adolescents of group 1 and group 2 (Table 1).

Table 1. The bullying structures (average value, in points).

\begin{tabular}{|l|c|c|}
\hline & Group 1 & Group 2 \\
\hline Bully & 7.23 & 4.74 \\
\hline Bully's assistant & 4.32 & 4.55 \\
\hline Defender & 12.52 & 12.13 \\
\hline Victim & 5.61 & 5.65 \\
\hline Bystander & 3.65 & 4.10 \\
\hline
\end{tabular}


The obtained data about the roles and positions taken by adolescents in the "bullying structure" (the bully, the bully's assistant, the defender, the victim, the bystander) are distributed in different proportions and indicate differences in the studied groups.

Then, we used "Buss-Perry Aggression Questionnaire" (adapted by S.N. Enikolopov, N.P. Tsibulsky) to study physical aggression, verbal aggression, anger and hostility in respondents. (Table 2).

Table 2. The results of "Buss-Perry Aggression Questionnaire" (adapted by S.N. Enikolopov, N.P. Tsibulsky) (average value, in points).

\begin{tabular}{|l|c|c|}
\hline & Group 1 & Group 2 \\
\hline Physical aggression & 21.23 & 23.58 \\
\hline Verbal aggression & 15.03 & 14.71 \\
\hline Anger & 20.42 & 17.96 \\
\hline Hostility & 20.55 & 22.13 \\
\hline
\end{tabular}

The results show that in both groups teenagers tend to a greater extent to express their aggression physically than verbally.

"The school anxiety test" (by Phillips) helped us to determine the level and the nature of anxiety of our respondents. The understanding of school anxiety includes "various aspects of stable school emotional disadvantage", which manifest in "excitement, increased anxiety in educational situations and in the classroom, in expectation of a bad attitude towards oneself, a negative assessment from teachers, peers" (Table 3 ).

Table 3. The results of "The school anxiety test" (by Phillips) (average value, in points).

\begin{tabular}{|l|c|c|}
\hline & Group 1 & Group 2 \\
\hline General anxiety at school & 9.68 & 8.78 \\
\hline Experiencing the social stress & 5.48 & 5.20 \\
\hline Frustration of the need to achieve success & 6.39 & 6.23 \\
\hline Fear of self-expression & 2.29 & 2.58 \\
\hline Fear of a knowledge test situation & 3.35 & 3.10 \\
\hline Fear of fail to meet the expectations of others & 2.61 & 2.29 \\
\hline Low physiological stress resistance & 2.03 & 1.65 \\
\hline Problems and fears in relationships with teachers & 4.35 & 4.19 \\
\hline
\end{tabular}

The primary data of "The school anxiety test" (by Phillips) indicate that the respondents of group 1 have a slightly higher level of the school anxiety than the respondents of group 2 .

And the results of "Strategic Approach to Coping Scale, SACS" (by S.E. Hobfoll adapted by N.E. Vodopyanova, E.S. Starchenkova) are represented in Table 4. The purpose of this technique is to determine a human behavior based on the types of reaction in a stressful situation.

Table 4. The results of "Strategic Approach to Coping Scale, SACS" (by S.E. Hobfoll adapted by N.E. Vodopyanova, E.S. Starchenkova) (average value, in points).

\begin{tabular}{|l|c|c|}
\hline & Group 1 & Group 2 \\
\hline Assertive action & 22.61 & 20.94 \\
\hline Social Joining & 24.16 & 22.53 \\
\hline Seeking social support & 25.03 & 23.03 \\
\hline Cautious action & 21.28 & 20.16 \\
\hline Instinctive action & 19.23 & 20.03 \\
\hline Avoidance & 17.32 & 18.16 \\
\hline Indirect action & 18.42 & 17.74 \\
\hline Antisocial action & 16.32 & 18.66 \\
\hline Aggressive action & 18.50 & 18.65 \\
\hline
\end{tabular}


The primary data of "Strategic Approach to Coping Scale, SACS" (by S.E. Hobfoll adapted by N.E. Vodopyanova, E.S. Starchenkova) show that the intensity of coping models are also higher in group 1 than in group 2.

\subsection{The results of correlation analysis}

On the second stage of the empirical research, we carried out the Spearman's rank correlation analysis to reveal the correlations between bullying structures, coping strategies, and aggression of the adolescents.

The statistically significant correlations revealed in group 1 are represented in Table 5.

Table 5. The Spearman's rank correlation coefficients (group 1).

\begin{tabular}{|c|c|c|c|}
\hline Parameter 1 & Parameter 2 & $\mathrm{r}$ & $\mathrm{p}$-level \\
\hline Assertive action & Bully & 0.54 & $\mathrm{p}<0.01$ \\
\hline Assertive action & Defender & 0.36 & $\mathrm{p}<0.05$ \\
\hline Assertive action & Victim & -0.38 & $\mathrm{p}<0.05$ \\
\hline Instinctive action & Bully's assistant & 0.43 & $\mathrm{p}<0.05$ \\
\hline Instinctive action & Defender & -0.36 & $\mathrm{p}<0.05$ \\
\hline General anxiety at school & Bully & -0.42 & $\mathrm{p}<0.05$ \\
\hline General anxiety at school & Defender & -0.40 & $\mathrm{p}<0.05$ \\
\hline Low physiological stress resistance & Bully & 0.56 & $\mathrm{p}<0.01$ \\
\hline
\end{tabular}

The statistically significant correlations revealed in group 2 are represented in Table 6.

Table 6. The Spearman's rank correlation coefficients (group 2).

\begin{tabular}{|c|c|c|c|}
\hline Parameter 1 & Parameter 2 & $\mathrm{r}$ & $\mathrm{p}-$ level \\
\hline Instinctive action & Defender & 0.39 & $\mathrm{p}<0.05$ \\
\hline Instinctive action & Victim & -0.35 & $\mathrm{p}<0.05$ \\
\hline Avoidance & Bystander & 0.35 & $\mathrm{p}<0.05$ \\
\hline Aggressive action & Bully & -0.41 & $\mathrm{p}<0.05$ \\
\hline Aggressive action & Victim & 0.43 & $\mathrm{p}<0.05$ \\
\hline Physical aggression & Defender & -0.45 & $\mathrm{p}<0.05$ \\
\hline Physical aggression & Bystander & 0.38 & $\mathrm{p}<0.05$ \\
\hline Fear of fail to meet the expectations of others & Bully & -0.59 & $\mathrm{p}<0.01$ \\
\hline Fear of fail to meet the expectations of others & Defender & -0.39 & $\mathrm{p}<0.05$ \\
\hline Fear of fail to meet the expectations of others & Victim & 0.45 & $\mathrm{p}<0.01$ \\
\hline Fear of fail to meet the expectations of others & Bystander & 0.35 & $\mathrm{p}<0.05$ \\
\hline $\begin{array}{c}\text { Problems and fears in relationships with } \\
\text { teachers }\end{array}$ & Bully & -0.40 & $\mathrm{p}<0.05$ \\
\hline
\end{tabular}

The Spearman's rank correlation analysis proves that the correlations between bullying structures, coping strategies, and aggression have differences depending on the place of living of the adolescents.

\section{Discussion}

The research empirically revealed the preference for "bullying structures" and their correlations with coping strategies and aggression of adolescents, living in their own families and in social rehabilitation centers for minors, and studying in comprehensive schools, in the conditions of information risks of modern education.

Analyzing the primary data, we can conclude that in the group of adolescents living in their own families there is quite clear structure of preferable bullying structures: Defender Bully - Victim - Bully's assistant - Bystander. As for the group of adolescents living in social 
rehabilitation centers for minors there is a gap between the preferable role of Defender and other roles (Victim - Bully - Bully's assistant - Bystander) which are close to each other and can be changed depending on the situation.

The choice of Defender in both groups indicates the predisposition of adolescents to behave actively and positively. We can state that the protective function is quite relevant for the given age period and associated with the factor of adaptation in society.

There are also differences in the displays of aggression in the studied groups. The teenagers who live at homes are slightly less aggressive. Nevertheless, all respondents prefer Physical aggression to Verbal aggression that is also relevant for their age.

There are no significant differences in school anxiety of the teenagers and in coping strategies they prefer. Evaluating the results of correlation analysis, we can describe the portraits of the participants. Group 1, the adolescents, living in their own families, have the following characteristics:

The teenagers with a preferred bullying structure of "Defender" are less aggressive and less anxious. They are more responsive and sympathetic, guided by respect for themselves and others, and have a thoughtful behavior.

The teenagers who choose the bullying structure of "Bully" have a decreased level of "General anxiety at school" and "Low physiological stress resistance" and can express themselves as they want.

The bullying structure of "Victim" has got a negative correlation to "Assertive action" that is mean that being in the state of victim a teenager focuses on one's own feeling and cannot rationally think about the value of oneself and others.

The preferable structure of "Bully's assistant" is related to "Instinctive action" and in this case the adolescents' behavior depends on the situation. They can easily change the role from "Bully's assistant" to any other. We assume that to a great extant this depends on their meaning-value sphere which is in the process of forming in this age period.

It is important to note that in this group there are no statistically significant correlations between the bullying structure of "Bystander" and any coping strategies, components of aggression and anxiety.

Group 2, the adolescents, living in social rehabilitation centers for minors, have the following characteristics:

The teenagers who choose the bulling structure of "Defender" act instinctively, have a less level of "Physical aggression" and are not afraid of failing to meet the expectations of others.

According to the living conditions that is apart from the families, the bullying structure of "Victim" is expected from these respondents. Nevertheless, taking this role, the teenagers become more aggressive, behave less instinctively, and have "a Fear of fail to meet the expectations of others".

The teenagers with the preferable structure of "Bully" have a decreased level of aggression. They do not try to meet the expectations of others and are not afraid of teachers.

The adolescents with the bulling structure of "Bystander" prefer not to take part in the conflicts, can express physical aggression if it will be necessary, and try to meet the expectations of others.

In this group there are no statistically significant correlations between the bullying structure of "Bully's assistant" and any other studied phenomena.

\section{Conclusion}

Thus, our study proves the differences in preferable bullying structures and coping strategies, components of aggression and anxiety correlated to them depending on the place and conditions of living of teenagers. 
The novelty of the study includes the description of peculiarities of choosing coping strategies by adolescents, participating in bullying, living in their own families and in social rehabilitation centers for minors, and studying in comprehensive schools, in the conditions of information risks of modern education.

The obtained results are significant in the field of bullying research in relation to the coping strategies choosing by adolescents. And the research in general has broad prospects for practical application in counseling and psychological work with adolescents in comprehensive schools and social rehabilitation centers for minors.

The represented results of the study are consistent with research in this area and are to be further discussed and investigated.

\section{References}

1. V.V. Kulish, N.A. Matveeva, N.V. Tumbaeva, Bulletin of Altai State Pedagogical University 3(40), 28-32 (2019) doi 10.37386/2413-4481.

2. I.A. Baeva, Yu.P. Zinchenko, V.V. Laptev, Psychological resources of modern Russian adolescents' resilience to violence in the educational environment 9(3), 159-172 (2016) doi: 10.11621/pir.2016.0311.

3. S. Folkman, Stress, coping, and hope. Psychological Aspects of Cancer (A Guide to Emotional and Psychological Consequences of Cancer, Their Causes and Their Management, Springer US, New York, 2013) doi: 10.1007/978-1-4614-4866-2_8.

4. K.S. Shalaginova, T.I. Kulikova, S.A. Zalygaeva, Psychological science and education. 24(4), 62-71 (2019) doi: 10.17759/pse.2019240405.

5. A.A. Rean, A.A. Stavtsev, Educational issues 3, 37-59 (2020) doi: 10.17323/1814-95452020-3-37-59.

6. K.D. Khlomov, D.G. Davydov, A.A. Bochaver, Psychology and Law 9(2), 276-295 (2019) doi: 10.17759/psylaw.2019090219.

7. D. Olweus, Annual Review of Clinical Psychology 9, 751-780 (2013) doi: 10.1146/annurev-clinpsy-050212-185516.

8. C.R. Cook, K.R. Williams, N.G. Guerra, T.E. Kim, S. Sadek, School Psychology Quarterly 2(25), 65-83 (2010) doi: 10.1037/a0020149.

9. H. Gaffney, M.M. Ttofi, D.P. Farrington, Journal of School Psychology 85, 37-56 (2021) doi: 10.1016/j.jsp.2020.12.002.

10. C. Viejo, B. Leva, J. Paredes, R. Ortega-Ruiz, Psicothema 32(4), 533-540 (2020) doi: 10.7334/psicothema2019.223.

11. N. Sianko, D. Kunkel, M.P. Thompson, M.A. Small, J.R. McDonell, Journal of Youth and Adolescence 48(12), 2360-2376 (2019) doi: 10.1007/s10964-019-01132-w.

12. E.A. Casey, H.L. Storer, T.I. Herrenkohl, American Journal of Orthopsychiatry 88 (3). 335-345 (2018) doi: 10.1037/ort0000245.

13. E. Khatcherian, N. Zdanowicz, Psychiatria Danubina 30, S537-S540 (2018). PubMed: 30439842.

14. C. Salmivalli, Aggression and Violent Behavior 15(2), 112-120 (2010) doi: 10.1016/j.avb.2009.08.007.

15. Yu.V. Obukhova, V.O. Guryeva, Russian psychological journal 14(2), 118-134 (2017) doi: 10.21702/rpj.2017.2.7.

16. Yu.A. Rokitskaya, Bulletin of the Chelyabinsk State Pedagogical University 3, 220-233 (2018) doi: 10.25588/CSPU.2018.03.23. 